\title{
Prosiding
}

\section{\% 웅}

KONFERENSH NTERNASIONAL

KESUSASTRAAN

HOTEL SANTIKA BANGKA, 20-22 SEPTEMBER 2018

Sasura Menarraribar

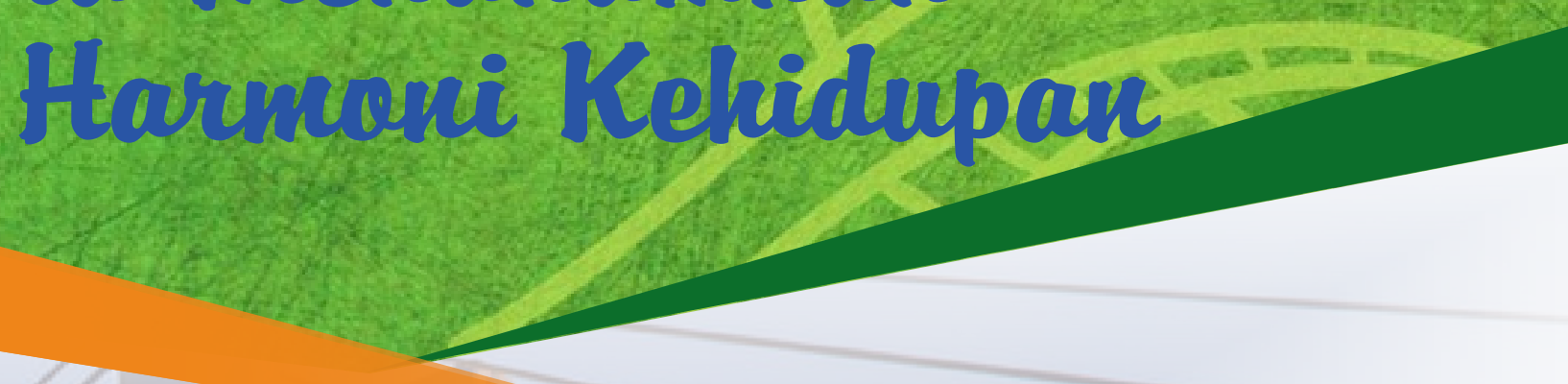

PEMBICARA UTAMA

Dr. H. Erzaldi Rosman Djohan, S.E., M.M.

(Gubernur.Kepulauan Bangka Belitung)

Prof. Dr. Suminto A. Sayuti

(Universitas Négeri Yogyakarta)

Dr. Dick Van Der Mej

(Leiden University Netherland)

Prof. Dr. Mohamad Mohktar Abu Hassan (Úniversitas Maláyá, Malaysia)

\section{Dr. Gautam Kumar Jha}

(Javaharal Nehru Úniversity, New Delhi, India)
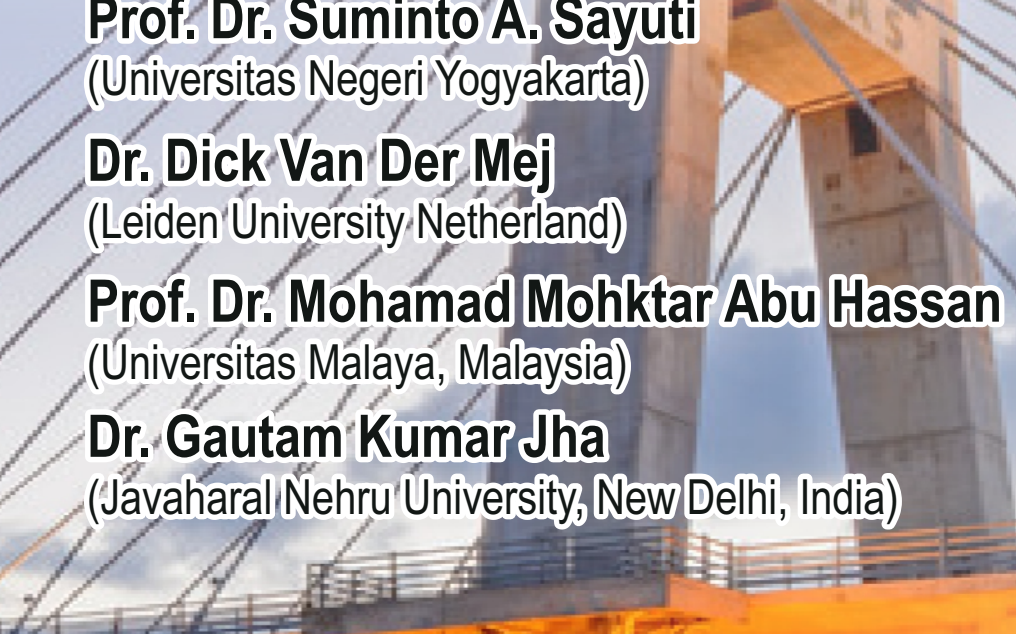

XXVII 


\section{Prosiding \\ KONFERENSI INTERNASIONAL KESUSASTRAAN XXVII \\ "Sastra Menanamkan Harmoni Kehidupan"}

Hotel Santika Bangka, 20-22 September 2018

Tim Reviewer:

Prof. Dr. Suwa rdi Endraswa ra, M .Hum. (Univ. Negeri Yogyaka rta)

Prof. Dr. Riris K. Toha Sa rumpa et, M .A. (Universita s Indonesia)

Prof. Dr. Setya Yuwa na Sudikan, M.A. (Univ. Negeri Surabaya)

Prof. Dr. Ali Imron Makruf, M .Hum. (Univ. Muhamma diya h Suraka rta)

Prof. Dr. Maryeni (Universitas Negeri Malang) 
Perpusatakaan Nasional: Katalog dalam Terbitan (KDT)

Prosiding

KONFERENSI INTERNASIONAL KESUSASTRAAN XXVII

"Sastra Menanamkan Harmoni Kehidupan"

Hotel Santika Bangka, 20-22 September 2018

Penanggung Jawab:

Dr. Asyraf Suryadin, M.Pd.

Drs. Hidayatul Astar, M.Hum.

Tim Reviewer:

Prof. Dr. Suwardi Endraswara, M.Hum.

Prof. Dr. Riris K. Toha Sarumpaet, M.A.

Prof. Dr. Setya Yuwana Sudikan, M.A.

Prof. Dr. Ali Imron Makruf, M.A.

Prof. Dr. Maryeni

Tim Editor:

Dra. Tien Rostini, M.Pd.

Maulina Hendrik, M.Pd.

Agci Hikmawati, M.Pd.

Sasih Karnita Arafatun, M.Pd.

Prima Hariyanto, S.Hum.

Rindu Handayani, M.Pd.

Feni Kurnia, M.Pd.

Fazrul Sandi Purnomo, M.Pd.

Nurfitriani, M.Pd.

Penata Letak dan Desain:

Gatot Afrianto, S.Sos.I.

Purwoko, A.Md.

\section{Penerbit:}

\section{STKIPMBB PRESS}

Komplek Perguruan Tinggi Muhammadiyah

Jalan K.H. Ahmad Dahlan Km. 4

Kel. Keramat, Kec. Rangkui, Kota Pangkalpinang, Provinsi Kep. Bangka Belitung telpon/ faks.: 0717-431771, surel: stkip.mbb@gmail.com, situs web: stkipmbb.ac.id

Cetakan 1, September 2018

Hak Cipta Dilindungi Undang-undang

All Right Reserved

\section{ISBN : 978-979-19917-9-7}

Sanksi Pelanggaran Pasal 72

Undang-Undang Nomor 19 Tahun 2002

Perubahan atas Undang-Undang Nomor 7 Tahun 1987

Perubahan atas Undang-Undang Nomor 6 Tahun 1982

Tentang Hak Cipta

1. Barang siapa dengan sengaja dan tanpa hak melakukan perbuatan sebagaimana dimaksud dalam Pasal 2 ayat (1) atau Pasal 49 ayat (1) dan ayat (2) dipidana dengan pidana penjara masing-masing paling singkat 1 (satu) bulan dan/atau denda paling sedikit Rp. 1.000.000,00 (satu juta rupiah), atau pidana penjara paling lama 7 (tujuh) tahun dan/atau denda paling banyak Rp 5.000.000.000,00 (lima miliar rupiah).

2. Barang siapa dengan sengaja menyiarkan, memamerkan, mengedarkan atau menjual kepada umumsuatu ciptaan atau barang hasil pelanggaran Hak Cipta atau Hak Terkait sebagaimana dimaksud dalam ayat (1), dipidana dengan pidana penjara paling lama 5 (lima) tahun dan/atau denda paling banyak Rp500.000.000,00 (lima ratus juta rupiah). 


\section{Sambutan}

\section{Ketua HISKI Komisariat Bangka Belitung}

\section{Asalamualaikum Warahmatullahi Wabarakatuh}

Salam Sastra,

Menulis merupakan cerminan karakter. Orang yang menulis pasti sering membaca, sedangkan orang yang gemar membaca belum tentu menulis. Secara tidak langsung, seseorang yang gemar menulis telah terbentuk karakternya dari sesuatu yang ia baca. Menulis memang bukanlah hal yang mudah seperti melisankan katakata. Namun, hasil menulis akan membuat orang lain percaya bahwa "saya pernah ada" bak pepatah mengatakan "saya menulis, maka saya ada".

Pramodya Ananta Toer dalam bukunya Bumi Manusia mengatakan orang boleh pintar setinggi langit, tapi selagi tidak menulis dia akan hilang dari sejarah. Selain menjadi sumber rujukan dalam berbagai disiplin ilmu, sebuah tulisan akan memberikan kesan tersendiri bagi setiap penulisnya di mata orang yang membaca.

Buku ini merupakan satu di antara bukti empiris bahwa para sastrawan, ahli bahasa telah menunjukkan keberadaannya. Buku ini juga merupakan bukti akademik yang menjadi tradisi tahunan bahkan menjadi kompetensi profesional yang sudah mendarah daging. Oleh karena itu, atas nama pimpinan Himpunan SarjanaKesusastraan Indonesia (HISKI) Komisariat Bangka Belitung dan Keluarga Besar STKIP Muhammadiyah Bangka Belitung, Saya mengucapkan terima kasih kepada pembicara utama, pemakalah pendamping, dan partisipan lainnya yang telah berpartisipasi dalam penyelenggaraan kegiatan ini. selamat bertukar pikiran dalam mengembangkan bahasa dan sastra untuk masa depan yang lebih baik khususnya di Indonesia dan dunia Internasional pada umumnya.

Terkhusus, saya ucapkan terima kasih dan selamat kepada seluruh panitia yang telah bekerja dengan sungguh hingga kegiatan ini terlaksana dengan baik dan lancar. Melalui kesempatan ini pula, Saya menghaturkan permohonan maaf kepada peserta yang berasal dari berbagai daerah se-Indonesia dan luar negeri apabila dalam penyelenggaraan konferensi ini terdapat kekurangan.

Terima kasih

Nasrun Minallah wa Fathun Qorib

Asalamualaikum Warahmatullahi Wabarakatuh

Bangka Tengah, 20 September 2018

Dr. H. Asyraf Suryadin, M.Pd.

Ketua HISKI Komisariat Bangka Belitung 


\section{Pengantar}

Keberagaman sastra merupakan gambaran kehidupan yang beragam. Sastra merupakan ungkapan berbagai bidang sosial masyarakat. Bicara tentang sastra, bicara pula tentang harmonisasi. Adanya keberagaman masyarakat bukan berarti hilangnya prinsip harmonisasi. Sastra hadir di tengah masyarakat untuk menciptakan perdamaian. Rumpun bahasa dan sastra Program Studi Pendidikan Bahasa Inggris STKIP Muhammadiyah Bangka Belitung bekerja sama dengan HISKI Komisariat Bangka Belitung dan HISKI Pusat menyelenggarakan Konferensi Internasional Kesusasatraan (KIK) XXVII di Provinsi Kepulauan Bangka Belitung pada 20-22 September 2018 dengan mengusung tema "Sastra Menanamkan Harmoni Kehidupan".

Pada konferensi ini disajikan 5 pembicara tamu dan 98 makalah pendamping yang berasal dari berbagai instansi di seluruh Indonesia dan luar negeri yang merujuk ke berbagai tema pokok di antaranya sastra terapan (pragmatika), interdisipliner sastra, pengembangan sastra, serta sastra dan pendidikan. Makalah yang disajikan diterbitkan dalam Prosiding Konferensi Internasional Kesusasatraan (KIK) XXVII dan beberapa Jurnal Bereputasi. Makalah tersebut telah melewati berbagai penilaian dari tim reviewer dan penyuntingan oleh tim editor berdasarkan format yang telah disepakati. Panitia mengucapkan terima kasih kepada tim reviewer dan tim editor yang telah bekerja sama dengan baik sehingga prosiding ini terselesaikan.

Pelaksanaan KIK XXVII tentunya merupakan hasil kerja keras bersama seluruh panitia yang didukung oleh Kantor Bahasa Kepulauan Bangka Belitung, Pemerintah Provinsi Kepulauan Bangka Belitung, Pemerintah Kota Pangkalpinang, Pemerintah Kabupaten Bangka Tengah, dan berbagai pihak sponsor. Oleh karena itu, Saya selaku ketua panitia menyampaikan rasa terima kasih kepada seluruh panitia yang telah bersungguh-sungguh menyiapkan kegiatan ini sehingga dapat berjalan dengan baik dan lancar.

Meskipun prosiding atau kumpulan artikel ilmiah konferensi, penyajian buku ini telah diupayakan agar "segar" dibaca. Namun, apabila dipandang pembaca belum memenuhi kriteria penyajian yang ideal, tentunya kami sangat bersenang hati menerima segala saran dan kritikan karena dengan demikian untuk penyajian yang akan datang dapat berkolaborasi dalam menyusun buku yang ideal itu. Semoga buku ini bermanfaat bagi siapa pun untuk menambah wawasan khususnya di dunia sastra.

Bangka Tengah, 20 September 2018

Iful Rahmawati Mega, M.Pd. Ketua Panitia 


\section{Sekapur Sirih}

\section{Seperti Wasit Sepak Bola}

Mungkin ini yang lebih tepat. Barangkali ini yang lebih metaforik. Saat momen piala dunia (bola) bergema, permintaan sekapur sirih ini muncul. Dari panitia lokal Bangka Belitung, yang sangat gigih, menjadi reviewer paper yang tersaji pada prosiding Konferensi Internasional Kesusastraan (KIK) XXVII ini, mirip wasit sepak bola. Mengapa?

Ketika peluit panjang kami tiup, diam-diam, ada "pemain" yang protes, "Mengapa papernya tidak masuk jurnal, kok masuk prosiding”. Hal ini gara-gara, penghargaan jurnal dan prosiding selalu dibedakan. Padahal, hakikat nuansa dan semangatnya sama. Ada lagi yang protes, mengapa papernya ditolak? Berkali-kali dijelaskan lewat whatsapp, baru sadar bahwa paper yang dibuat itu ternyata bukan membahas sastra, padahal semua paham HISKI itu jelas membahas tentang sastra.

Apapun konsekuensinya, kami tetap harus memutuskan. Seorang wasit, kadang-kadang harus ikut ke mana bola liar itu ditendang. Kadang harus lari ke sana kemari, seperti ingin sekali ikut menendang atau menyundul bola pakai kepala. Sebagai reviewer, terus terang kami merasa "gatal" ketika mencermati karya temanteman anggota dan pengurus HISKI. Menurut hemat kami, ada dua kategori paper, yaitu (1) paper sebagai hasil penelitian, yang kadang dilupakan istilah-istilah teknis masih terbawa ke paper ini, (2) paper yang masih berkutat pada perspektif modern, belum berani menampilkan paper-paper yang spektakuler.

Sebagai wasit, seperti di permainan sepak bola, kami memahami bahwa istilah "kartu merah" sengaja kami hindari sekecil mungkin. Kami lebih mengedepankan ihwal "kartu kuning', untuk melakukan pembinaan agar temanteman lebih bersemangat. KIK XXVII ini adalah ladang pengembangan kajian-kajian sastra. Beberapa penulis muda memang tampak bergairah, membidik hal-hal unik dalam peta sastra kita. Karena itu, kami selaku reviewer harus bangga.

Yang tersaji dalam prosiding ini, tentu masih ada kelemahan. Bahkan kalau menangkap teman-teman yang kami mohon me-review, harus berkata "sebenarnya banyak yang kurang menggigit", namun jika tidak terlalu fatal tentu perlu dibina. Kami lebih banyak ikut mengalir, ketika membaca paper teman-teman. Akhirnya, dari paper yang dikirimkan sejumlah 90-an lebih, harus "goolllll" melewati gawang. Bukan berarti penjaga gawangnya lengah, namun lebih pada aspek saling bertegur sapa akademik. Sebuah karya itu memang tidak akan pernah final.

Untuk itu, atas nama ketua umum HISKI Pusat dan sekaligus sebagai koordinator tim reviewer kami ucapkan terima kasih kepada: (1) Tim reviewer, yang terdiri dari Prof. Riris K Toha Sarumpaet, MA, Ph.D, Prof. Dr. Setya Yuwana Sudikan, MA, Prof. Dr. Maryeni, M.Pd., Prof. Dr. Ali Imron Makruf, M.Hum, dan Prof. Dr. Suwardi Endraswara, M.Hum, mereka adalah senior di bidang sastra yang tidak perlu diragukan lagi sebagai “wasit' yang bijak, (2) Ketua HISKI Komisariat 
Bangka Belitung yang telah memberikan peluang penyelenggaraan KIK XXVII, hingga pada tanggal 20-22 September 2018 ini dapat terlaksana, (3) Pemerintah Provinsi Kepulauan Bangka Belitung, yang telah menyambut, memfasilitasi, dan mengapresiasi kehadiran kami, (4) Ketua STKIP Muhammadiyah Bangka Belitung, (5) Segenap panitia lokal Bangka Belitung atas kerja samanya. Dengan kerja sama sinergis, prosiding ini dapat diterbitkan. Semoga paper yang terbit dalam prosiding ini memberikan peluang kebaruan pemahaman sastra yang dapat menjaga harmoni kehidupan.

Akhirnya, kami ucapkan selamat membaca. Kritik dan saran tentu kami buka seluas-luasnya. Semoga tulisan dalam prosiding ini memancing diskusi lebih hangat untuk meraih makna yang hakiki. Terima kasih. Kami ucapkan selamat melaksanakan konferensi. Salam HISKI: Jaya berkarya. Sukses selalu.

Tim Reviewer

Prof. Dr. Suwardi Endraswara, M.Hum., dkk. 
DAFTAR ISI

SAMBUTAN KETUA HISKI KOMISARIAT BANGKA BELITUNG iv PENGANTAR KETUA PANITIA V

SEKAPUR SIRIH Vi

JADWAL PEMAKALAH PENDAMPING

DENAH RUANG PARALEL

DAFTAR ISI

HANSEL AND GRETEL: A WITCH HUNTER'S

SEBUAH BENTUK EKRANISASI DONGENG HANSEL AND GRETEL

Adita Widara Putra

KECERDASAN EKOLOGIS LEGENDA ENDANG RARA TOMPE 24 YANG DITRANSFORAMASI DALAM PERTUNJUKAN KETHEK OGLENG PACITAN

Agoes Hendriyanto, Arif Mustofa, Bakti Sutopo

NILAI KARAKTER DALAM SYIIRAN DI WILAYAH PESISIR 34 PANTAI UTARA JA WA TENGAH

Agus Nuryatin dan Muhamad Burhanudin

MENAFSIR ULANG MASA AWAL SASTRA INDONESIA MODERN

Ahmad Bahtiar

SIGNIFIKANSI TEATER DALAM PENDIDIKAN KARAKTER

Ali Imron Al-Ma'ruf

SEKS BEBAS BUKAN SEBAGAI TINDAKAN RADIKAL DALAM

NOVEL RONGGENG DUKUH PARUK KARYA AHMAD TOHARI:

KAJIAN PSIKOANALISIS-HISTORIS SLAVOJ ZIZEK

Aryana Nurul Qarimah dan Dyani Prades Pratiwi

SUBJEK GAGAL DALAM NOVEL DI KAKI BUKIT CIBALAK 101 KARYA AHMAD TOHARI DALAM PRESPEKTIF SLAVOJ ZIZEK Buyung Ade Saputra 
SASTRA ANAK BERBASIS CERITA RAKYAT: NOSTALGIA 119 DALAM KEARIFAN NUSANTARA

Cahyaningrum Dewojati

HUBUNGAN PENGETAHUAN STRUKTUR CERITA PENDEK DAN 146 KEMAMPUAN BERPIKIR KRITIS DENGAN KEMAMPUAN MENGAPRESIASI CERITA PENDEK

(Penelitian Korelasional di Kelas XI SMA Labschool Jakarta)

Chairunnisa

MENGKONSTRUKSI NARASI KEBANGSAAN: REVITALISASI 163 NILAI-NILAI PANCASILA PADA CERITA ANAK INDONESIA DEMI PEMBANGUNAN KARAKTER MANUSIA INDONESIA YANG PANCASILAIS

Clara Evi Citraningtyas, Hananto, Paulus Heru Kurniawan

$\begin{array}{llllll} & \text { NILAI-NILAI LUHUR } & \text { DALAM } & \text { CERITA } & \text { RAKYATI } & 173\end{array}$ DARAMATASIA

Dafirah

KONTRIBUSI TEMBANG DOLANAN BAGI PERKEMBANGAN KEPRIBADIAN ANAK

183

Daru Winarti

MEMBACA KEMBALI UNDANG-UNDANG NOMOR 5 TAHUN 202 2017 TENTANG PEMAJUAN KEBUDAYAAN; SEBUAH UPAYA PERLINDUNGAN DAN PELESTARIAN BUDAYA INDONESIA SECARA KESELURUHAN

Dwi Oktarina

SASTRA LISAN UNGKAPAN LARANGAN KATEGORI KOSMIK

DAN CUACA DALAM MASYARAKAT MINANGKABAU (SASTRA DALAM WAWASAN CULTURAL)

Elkartina S dan Ratmiati

PEMAKNAAN TERAHADAP TANAMAN ADAT SEBAGAI USAHA PELESTARIAN BUDAYA MASYARAKAT GORONTALO

Ellyana Hinta

PEMBELAJARAN SASTRA ANAK DI INDONESIA: PROBLEMA 242 DAN SOLUSI

Esti Ismawati \& Wisnu Nugroho Aji 
PELUANG DAN TANTANGAN PENGEMBANGAN SASTRA 255 INDONESIA

Fatmah AR. Umar

PARODI DALAM NOVEL MEMBURU AURA KEN DEDES KARYA 271 MUSTOFA W HASYIM

Fitri Merawati

OMEROS AND ITS CARIBBEAN SEA AS THE REVIVAL OF 285 CLASSICAL GREEK MYTHOLOGY

Gabriel Fajar SA

MAKNA LINGUISTIK, MAKNA KULTURAL， DAMPAK 299 PSIKOLOGIS GUGON TUHON TERHADAP PERILAKU MASAYARAKAT LEBAKHARJO, KABUPATEN MALANG

Givari Jokowali dan Imro'atul Mufiddah

ANALYSIS OF LOCAL WISDOM IN CHILDREN'S STORY AS AN 310 EFFORT TO INTRODUCE INDONESIAN CULTURE TO THE INTERNATIONAL WORLD

Hera Wahdah Humaira

PROSESI RITUAL UPACARA ADAT SUKU ASMAT DALAM 329 NOVEL NAMAKU TEWERAUT KARYA ANI SEKARNINGSIH (Kajian Antropologi Sastra)

Herman Didipu

UPAYA AHMAD TOHARI MELAWAN KORUPSI DALAM NOVEL 341 ORANG-ORANG PROYEK

Herson Kadir

ETNOPUITIKA RELIGI DAN DAKWAH KULTURAL 'SYI'IR 354 SUROBOYOAN" KH MOENTOWI

Heru Subrata

MARITIME TRACES IN FRANS NADJIRA'S POEMS

I Gusti Ayu Agung Mas Triadnyani

KISAH PERTEMUAN RAMA DAN PAKSI JATAYU: SEBUAH 378 REFLEKSI KEHARMONISAN DALAM KEHIDUPAN

I Ketut Jirnaya 
THE IDEOLOGIES BEHIND THE MIXED MARRIAGE IN THE 389 HARDJANA HP'S NOVEL YANG TAK TERGOYAHKAN

I Ketut Sudewa

BERTEMU PUTRI MANDALIKA DI PANTAI SELATAN: DALAM 406 PERSPEKTIF PARIWISATA SASTRA

I Made Suyasa

PROFIL KEMAMPUAN LITERASI SISWA SEKOLAH DASAR 423 DALAM MENULIS PUISI BAHASA INDONESIA DENGAN MODEL EXPERIENTIAL LEARNING

Isah Cahyani dan Ratmi

MULTIKULTURALISME DALAM NOVEL CINTA PUTIH DI BUMI 433 PAPUA KARYA DZIKRI EL HAN

Jafar Lantowa dan Zilfa A. Bagtayan

PENDIDIKAN LINGKUNGAN DALAM CERPEN MEDIA DARING 443 INDONESIA SEBAGAI SARANA HARMONISASI KEHIDUPAN MANUSIA DENGAN ALAM

Juanda

HEGEMONI POLITIK DALAM SASTRA LISAN DI DAERAH EKS 470 KARESIDENAN PATI

Kustri Sumiyardana

CERITA ANAK INDONESIA: MEMPERTEMUKAN HANTU 488 TIMUR DAN BARAT DALAM SERIAL GHOST SCHOOL DAYS

Lina Meilinawati Rahayu

PEREMPUAN YANG MENGINGINKAN CINTA DAN KEADILAN 506 DALAM DRAMA DER BESUCH DER ALTEN DAME KARYA FRIEDRICH DÜRRENMAT

Lutfi Saksono

KULINER DALAM KARYA SASTRA: PERSPEKTIF 520 GASTROCRITICISM

Mareta Dwi Artika 
$\begin{array}{lllll}\text { LITERASI SEKOLAH TINGKAT PEMBELAJARAN DALAM } 548 & \end{array}$ "PRESSLIST" SMAN 3 DENPASAR BALI

Maria Matild is Banda

STRATEGIES INVOLVING STUDENTS' CREATIVITY \& 572 EXTENSIVE READING FOR A BETTER BOOK REPORT COURSE

Maria Vincentia Eka Mulatsih

TUTURAN ADAT DALAM UPACARA TOA PEO PADA 583 MASYARAKAT DESA WOLOEDE KECAMATAN MAUPONGGO KABUPATEN NAGEKEO

Maria Yulita C. Age

BUKU PENGAYAAN APRESIASI CERITA ANAK BERMU $t_{t} 602$ UNGKAPAN JAWA: POTENSI DAN PRINSIP PENGEMBANGANNY $f$ Meina Febriani

SASTRA RUSIA DALAM TERJEMAHAN INDONESIA: ANTARA 617 PILIHAN POLITIK, MASYARAKAT, DAN PASAR

Mina Elfira

KAJIAN STILISTIKA DALAM DAKWAH K.H ZAENUDIN MZ

633

Misra Nofrita dan M.Hendri

FOLKLORE DALAM LEGENDA DANAU LIMBOTO

642

Moh. Karmin Baruadi dan Sunarty Eraku

UNSUR EDUKASI ANAK DALAM CERPEN "KANCIL DAN 656 BUAYA" KARYA SYRLI MARTIN (Kajian Sastra Anak Melalui Semiotika Roland Barthes)

Mohammad Iqbal Olii dan Jafar Lantowa

KRITERIA MATERI AJAR PUISI DI SD

Mukh Doyin

Muliadi dan Kasma F.Amin 
PEMBELAJARAN MENULIS FIKSI CERPEN MELALUI 716 STRATEGI MENIRU, MENGOLAH, MENGEMBANGKAN (3M) PADA SISWA KELAS XI SEKOLAH MENENGAH ATAS

Mursalim

PEMAKAIAN UNGGAH-UNGGUH BASA JAWA DALAM ROMAN 729 PARA PAWESTRI PEJUWANG

Nanik Herawati

MODIFIKASI MATERI KABA MINANGKABAU SEBAGAI 740 BACAAN PESERTA DIDIK

Ninawati Syahrul

SASTRA PESISIR DAN AGRARIS OPTIMALISASI EKONOMI 760 KREATIF BERBASIS SASTRA

Novi Anoegrajekti dan Sudartomo Macaryus

PENOLAKAN NARASI BESAR DALAM NOVEL GADIS PANTAI 773 KARYA PRAMOEDYA ANANTA TOER (Kajian Dekonstruksi Jacques Derrida)

Nur Fitri Yanuar Misilu

HIGHLIGHTING THE CONCEPT OF HUMAN RIGHTS THROUGH 790 SOME AMERICAN INTELLECTUAL WRITINGS OF THE PURITAN AND REVOLUTIONARY ERAS

Nuriadi

$\begin{array}{lllllll}\text { THE IMPLEMENTATION OF CORPUS LINGUISTICS IN } & 2^{\text {st }} & 802\end{array}$ CENTURY

Pratiwi Amelia

MEMBACA SHELDON DALAM HANACO: LES MASQUES

Resti Nurfaidah

PENGELOLAAN DAN PEMANFAATAN AIR SEBAGAI UPAYA 831 KONSERVASI SUMBER DAYA AIR PADA MASYARAKAT ADAT Ridzky Firmansyah Fahmi dan Syihabuddin 
PEMBELAJARAN SASTRA MELALUI CERPEN BERBASIS 846 KARAKTER BUILDING SEBAGAI UPAYA MENANAMKAN JIWA PANCASILAIS PADA GENERASI MILENIAL

Ririh Rubus Setyaningrum

ANALISIS STRUKTUR TEKS, KONTEKS, KO-TEKS, PROSES 856 PEWARISAN, FUNGSI, DAN NILAI RITUAL CINGCOWONG DI KABUPATEN KUNINGAN JAWA BARAT

Rosi Gasanti

$\begin{array}{llllll}\text { KEBINEKAAN SEBAGAI MODALITAS BUDAYA } & \text { UNTUK } & 879\end{array}$ MEMPERKUKUH KARAKTER BANGSA

Rosida Tiurma Manurung dan Trisnowati Tanto

REFRENSENTASI KEHIDUPAN MASYARAKAT DALAM CERITA 892 RAKYAT LAHILOTE

Sance A. Lamusu

$\begin{array}{lllllll}\text { ESTHETIC VALUE PAPANTUNG IN SANGIHE SUKU } & 913\end{array}$ TRADITIONAL CUSTOMARY SOCIETY IN MANENTE VILLAGE, TAHUNA DISTRICT, NORTH SULAWESI PROVINCE

Sarleoki Nancy Umkeketony

HIBRIDITAS DAN MULTIKULTURAL DALAM CERITA RAKYAT 921 PULAU TIDUNG SEBAGAI PEMERSATU MASYARAKAT PULAU SERIBU

Siti Gomo Attas

COMPOSITION OF KANA INAI ABANG NGUAK IN MILMAN PARRY 936 AND ALBERT B. LORD PERSPECTIVE

Sri Astuti dan Yoseph Yapi Taum

GENDER, CELOTEHAN BAHASA, DAN OCEHAN SASTRA

Sri Mulyani

DINAMIKA LINGKUNGAN BUDAYA DALAM NOVEL JATISABA 973 KARYA RAMAYDA AKMAL

Sugiarti 
CATATAN SINGKAT ILMU PANYANDRAN (KATURANGGAN)

DALAM SĔRAT CANDRAWARNA

Sumarsih

TRADISI LISAN DALAM ILMU ANTROPOLOGI

1008

Sumiman $U d u$

MEMBACA EKRANISASI, MEMBINCANGKAN POLEMIK 1026 POLIGAMI, DAN MEMBUDAYAKAN LITERASI

Suseno

POLA PIKIR DAN SUDUT PANDANG NOVEL-NOVEL JAWA 1038 PRAKEMERDEKAAN

Teguh Supriyanto dan Sucipto Hadi Purnomo

KRITIK SOSIAL DALAM TEKS DRAMA PENEMBAK MISTERIUS 1054 KARYA RADHAR PANCA DAHANA

Tiya Antoni dan Burhan Sidik

$\begin{array}{lllllll}\text { STRUCTURAL AND } & \text { FUNCTIONAL DEMANDS OF } & \text { ROALD } & 1068\end{array}$ DAHL'S CINDERELLA

Trisnowati Tanto dan Rosida Tiurma Manurung

DEKONSTRUKSI NILAI BUDAYA DALAM KEHIDUPAN 1078 BERAGAMA PADA NOVEL ELEGI CINTA MARIA KARYA WAHEEDA EL- HUMAYRA

Vedia, Aceng Rahmat, dan Izzah

FINDING THE VOICE OF THREE LEARNER WRITERS' POEMS 1101 IN CREATIVE WRITING CLASS OF ENGLISH LETTERS DEPARTMENT, SANATA DHARMA UNIVERSITY

Wedhowerti

PENGARUH PROSES PENERJEMAHAN PADA FAKTA CERITA 1110 NOVEL YUKIGUNI KARYA KAWABATA YASUNARI DAN DUA VERSI TERJEMAHAN BAHASA INDONESIA

Wiastiningsih 
PENTINGNYA PENYUSUNAN SILABUS SEJARAH SASTRA ANAK 1136 INDONESIA UNTUK PEMBELAJARAN BACAAN DAN PENULISAN SASTRA ANAK BERKUALITAS

Wikan Satriati

NOVEL AS A HISTORICAL WITNESS OF THE 30 ${ }^{\text {TH }}$ SEPTEMBER 1149 MOVEMENT IN INDONESIA: A READING OF MANJALI AND CAKRABIRAWA BY AYU UTAMI

Wiyatmi

TEACHING WRITING SHORT STORY USING CIRCUIT 1169 LEARNING MODEL

Yeyen Yusniar, Novi Santi, dan Triska Purnamalia

MEMBACA KEARIFAN LOKAL DALAM LAGU PENGANTAR 1179 TIDUR JAWA DAN SUNDA

Yulianeta

MENGENAL KEMBALI RAJA ALI HAJI “GURINDAM 12” DALAM 1193 PANDANGAN HARMONISASI NILAI-NILAI KEMANUSIAAN DULU DAN TETAP RELEVAN KINI

Yundi Fitrah

BUILDING CHILDREN CHARACTER AND READING INTEREST 1204 THROUGH CHILDREN'S LITERATURE LEARNING WITH EXTENSIVE READING METHOD

Zakridatul Agusmaniar Rane, Waode Ade Sarasmita Uke, dan Nuzul Hijrah Safitri

OPTIMALISASI MEDIA PEMBELAJARAN LITERASI SEBAGAI 1214 UPAYA PENGUATAN KARAKTER HUMANIS

Zuliyanti 


\title{
REPRESENTASI NILAI KEARIFAN LOKAL DALAM PUISI
}

\author{
Muliadidan Kasma F.Amin \\ Fakultas Sastra, Universitas Muslim Indonesia, Makassar \\ muliadi.muliadi@umi.ac.id
}

\begin{abstract}
ABSTRAK
Nilai adalah sesuatu yang baik dan berharga dalam hidup dan kehidupan manusia. Kalau demikian, setiap manusia pasti menginginkan nilai. Nilai terepresentasi dalam perbuatan atau dalam karya manusia. Karya manusia beraneka ragam dan salah satu di antaranya adalah karya sastra. Contoh karya sastra adalah novel, cerita pendek, drama, dan puisi. Karya sastra yang dibahas dalam tulisan ini hanya karya sastra yang berupa puisi. Puisi adalah representasi tindakan dan pemikiran dari sang kreator atau sang pemuisi setelah bergumul dengan dunia, baik dunia luar maupun dunia dalam batinnya. Puisi sebagai karya kreatif mengembang berbagai nilai, yakni nilai religius, nilai etis, nilai estetis, dan nilai filosofis. Di antara empat jenis nilai yang disebutkan itu hanya nilai filosofis yang dibahas dalam tulisan ini. Nilai filosofis yang dimaksud tersebut adalah nilai filosofis yang bernuansa: kesadaran diri, keberanian, dan harga diri. Metode yang digunakan untuk mengungkap nilai-nilai yang dimaksud tersebut adalah metode hermeneutika Ricoeur. Sumber data dalam tulisan ini adalah antologi puisi Perahu Badik: Membaca Laut, karya Aspar Paturusi, sedangkan datanya adalah kata, baris, dan bait dari puisi-puisi yang terkait dengan bahasan di atas.
\end{abstract}

Kata-kata Kunci: Representasi, Nilai Kearifan Lokal, dan Teks Puisi.

\section{ABSTRACT}

Values are the good and valuable things in human life. If so, every human being would want a value. Values are represented in deeds or in human works. Man's work is diverse and one of them is a literary work. Examples of literary works are novels, short stories, plays, and poems. The literary works discussed in this paper are only literary works in the form of poetry. Poetry is a representation of actions and thoughts of the creator or the pemuisi after struggling with the world, both the outside world and the inner world. Poetry as a creative work expands values, namely religious values, ethical values, aesthetic values, and philosophical values. Among the four types of values mentioned are only the philosophical values discussed in this paper. The philosophical value in question is a nuanced philosophical value: self-awareness, courage, and self-esteem. The method used to reveal the values in question is the hermeneutic method Ricoeur. The source of the data in this paper is the anthology of poetry Perahu Badik: Membaca Laut, the work of Aspar Paturusi, while the data is the words, lines, and verses of the poems related to the above discussion

Keywords: Representation, Value of Local Wisdom, and Text of Poetry. 


\section{PENDAHULUAN}

Karya sastra-termasuk juga puisi adalah bentuk dan struktur bahasamerupakan produk rekayasa tanda, berkedudukan sebagai eksistensi sekunder, yang terlahir dari sastrawan (Muliadi, 2014:1). Pemahaman demikian didasarkan bahwa dalam proses pelahiran karya sastra, ide telah mengada mendahului tanda, sehingga bentuk dan struktur bahasa sebagai eksistensi sekunder tidak dapat dipisahkan dengan pengadanya, yakni sastrawan. Konskuensi dari itu, maka adanya sastra (puisi), baik lisan maupun tulis bukan karena kehendak dirinya sendiri, melainkan karena kehendak dan harapan sastrawannya.

Puisi sebagai bentuk dan struktur khas kebahasaan adalah juga eksistensi sekunder. Hal ini berarti bahwa puisi mengada bukan karena kehendak dirinya sendiri, melainkan karena kehendak dan harapan penuturnya atau penulisnya. Dalam konteks keberwujudan atau keberadaan puisi tersebut, penutur dan atau penulis puisi berkedudukan dan berperan sebagai kreator, disebut penyair. Dalam konteks tersebut, proses yang ditindaki penyair saat mewujudkan atau melahirkan puisi dipahami sebagai proses kreatif atau proses memetamorfosiskan kehendak dan harapannya. Hal itu diketahui karena adanya kehendak dan harapan dalam ruang ide atau ruang batin penyair belum dapat disebut puisi jika belum mewujud atau mengada sebagai bentuk dan struktur khas kebahasaan. Dengan begitu, hubungan bentuk dan struktur puisi dengan kehendak dan harapan penyairnya dapat dipahami sebagai hubungan lahir dan batinnya, hubungan bentuk dan isinya, hubungan representamen dan pesannya, serta hubungan ekstrinsik terhadap intrinsiknya.

Keberadaan bentuk dan struktur puisi merupakan simbiosis sekaligus juga metamorfosis pengalaman, pengetahuan, dan pengakuan penyair atas keberadaan ruang dan waktu yang telah dijejakinya terhadap harapan dan kehendakkehendaknya. Dalam konteks tersebut, ruang dan waktu berarti sudah ada mendahului adanya kehendak dan harapan penyair.

Pemahaman tersebut tentu juga mengena pada Aspar Paturusi (AP) dalam seluruh proses kepenyairannya. Karena itu, keberadaan seluruh puisi AP sebagaimana terbaca dalam kumpulan puisinya yang berjudul Perahu Badik: 
Membaca Laut (Reading the Sea) dapat dipahami sebagai simbiosis dan sekaligus metamorfosis pengalaman, pengetahuan, dan pengakuannya atas ruang dan waktu atau fenomena alam dan sosial budaya yang telah dijejakinya terhadap harapan dan kehendak-kehendaknya. Dengan begitu, identitas, pengetahuan, pengalaman, serta pengakuan atas ruang dan waktu yang pernah dijejaki AP, serta harapan dan kehendak-kehendaknya dalam proses kepenyairannya akan dapat dikenali kembali pada dan dalam bentuk dan struktur puisi-puisinya.

Aspar Paturusi adalah salah seorang aktor nasional yang bermukim di Jakarta. Dia lahir pada tanggal 10 April 1943 di Bulukumba, Sulawesi Selatan. Pekerjaannya, selain aktor adalah juga menulis buku-buku sastra, seperti drama, novel, dan puisi. Puisi yang sempat dibukukan dalam lima tahun terakhir ini adalah antologi puisi Badik, 2011 dan antologi puisi Perahu Badik: Membaca Laut, 2015. Sementara itu, film yang pernah dibintanginya adalah film Latando di Tanah Toraja, Sanrego, Tragedi Bintaro, Tutur Tinular, Ketika Cinta Bertasbih I dan II, sedangkan sinetron yang pernah dibintanginya adalah Tukang Bubur Naik Haji dan Berkah.

Berdasarkan uraian latar belakang tersebut dapat dikatakan bahwa Aspar Paturusi (AP) sebagai penyair yang berasal dari Sulawesi Selatan telah mengintrodusir nilai-nilai kearifan lokal ke dalam teks puisinya. Misalnya: gunung yang puncak/gunung yang kukuh/gunung yang diam. Bait puisi tersebut dikutip dari puisi yang berjudul, "Gunung dan Laut". Puisi ini secara filosofis dapat menyaran pada sifat lempuk dari orang Bugis-Makassar. Nilai-nilai kearifan lokal seperti itulah yang perlu digali karena relevan dengan zaman sekarang ini, yang kita ketahui di mana-mana terjadi prilaku yang destruktif. Nilai-nilai kearifan lokal antara lain: nilai religius, nilai etis, nilai estetis, dan nilai filosofis. Namun, dalam artikel ini yang dibahas hanya nilai filosofis.

\section{KAJIAN PUSTAKA}

Berikut ini diuraikan secara singkat tentang refresentasi, nilai, dan kearifan lokal yang bernuansa nilai filosofis. 
Representasi berarti merekonstruksi dan menampilkan berbagai fakta dan pikiran dalam wujud bahasa (Ratna, 2005: 612). Karena itu sebagai representasi fakta dan pikiran dalam wujud bahasa, virtual puisi tidak sama dengan fakta dan pikiran yang direpresentasikannya. Dipahamai demikian, karena representasi puisi tidak bisa terlepas dari persepsi kreatornya (penyair). Karena itu menjadi pas jika puisi merupakan cermin, bayangan, gambaran dari sebuah kenyataan. Dalam bingkai tersebut, puisi dipandang sebagai pendeskripsian yang melambangkan kenyataan (Teeuw, 1984: 220). Oleh karena itu, karya sastra (puisi) mencerminkan masyarakatnya dan tidak terhindarkan pula dipersiapkan oleh keadaan masyarakat dan kekuatan-kekuatan pada zamannya (Abrams, 1981:178). Seorang penyair tidak dapat lepas dari pengaruh sosial budaya masyarakatnya, seperti terwujud dalam tokoh-tokoh yang dikemukakan, sistem kemasyarakatan, adat-istiadat, pandangan masyarakat, kesenian, dan benda-benda kebudayaan yang terungkap dalam karyanya (Pradopo, 2005:254).

Puisi sebagai representasi fakta dan pikiran mengajar manusia untuk mengenal diri sendiri, manusia lain, mahluk lain, alam semesta, dan Tuhan (Amir, 1990: 58). Pada pemahaman tersebut puisi mempersoalkan dan atau menyajikan kehidupan berkaitan dengan kejiwaan, pikiran, dan perasaan yang terbentuk oleh lingkungan sekitarnya (Jassin, 1977: 12). Dalam perjalanan hidup sastra dan manusia telah membangun dunia khas sastra yang kontemplatif religius, imajinatif, ilahiah, penuh damai, penuh kearifan, penuh teladan dan sebagainya (Saryono, 2009: 12).

Istilah nilai, 'value'[bahasa Inggris], 'valere'[bahasa Latin], 'valoir' [bahasa Perancis Kuno] secara umum memaknai pengertian keberhargaan atau kebaikan (Mulyana, 2004:7). Dalam Kamus Dewan (Iskandar, 1998:864), nilai berarti derajat, kualitas, mutu, taraf, sifat ketinggian pemikiran, agama, kemasyarakatan, dan lain-lain. Ini berarti nilai adalah sesuatu yang tinggi dan berharga, penting, dan sangat perlu bagi kehidupan manusia. Hal tersebut sejalan dengan Gazalba (1998:33) yang menyatakan bahwa nilai adalah sesuatu yang dipandang berharga oleh manusia atau kelompok manusia. 
Selain itu, Puteh (1996:25-26) menyatakan bahwa nilai merupakan suatu unsur yang terdapat dalam semua ajaran moral yang populer dan ia berdasarkan pengiktirafan bahwa individu dalam sesuatu kelompok sosial itu saling memerlukan satu sama lain. Nilai juga berupaya memberikan panduan bagaimana seseorang yang ideal itu harus bertindak dalam masyarakatnya. Dengan kata lain, nilai merupakan paradigma rujukan dalam menjaga dan mengatur perlakuan anggota masyarakat. Menurut Gabriel (1991:144) nilai adalah suatu ideal, suatu paradigma yang menyatakan realitas sosial yang diingini dan dihormati. Pada hakikatnya, nilai adalah kepercayaan-kepercayaan bahwa cara hidup yang diidealisasi adalah cara yang terbaik bagi masyarakat.

Ali ibn Abi Thalib (dalam al-Qarni, 2008: 178) mengatakan bahwa nilai manusia terdapat dalam perbuatan baik yang dia lakukan. Maknanya, ilmu pengetahuan manusia, adab kesopanannya, ibadah, kedermawanan, serta akhlak dan moralitasnya adalah nilai diri yang sebenarnya dan bukan wajah, gayah dan kedudukannya. Hal ini sesuai dengan (QS. Al-Baqarah:221) yang artinya, "Sesungguhnya budak yang mukmin lebih baik daripada orang musyrik, walaupun dia menarik hatimu."

Sulawesi Selatan merupakan wilayah yang multikultural. Hal ini ditandai dengan adanya beberapa suku bangsa yang mendiami wilayah ini, yaitu suku Bugis, Makassar, Toraja, dan Mandar serta setiap daerah memiliki kearifan lokal. Suku Mandar sejak tahun 2004 telah berpisah dari Sulawesi Selatan, Mandar masuk dalam wilayah/ Provinsi Sulawesi Barat sebagai pemisahan atau pemecahan Provinsi Sulawesi Selatan.

Menurut Baharuddin Lopa (dalam Mustafa dkk, 2003: 52-65) kearifan lokal Sulawesi Selatan secara umum memiliki kesamaan dengan keempat suku di atas. Misalnya, siri' dalam bidang kesusilaan, apabila ada seorang pria memperkosa seorang gadis maka keluarga si gadis merasa berhak membunuh si pria tersebut. Pria tersebut bisa lolos dari ancaman apabila ia melaporkan dirinya kepada Kepala Adat setempat. Kalau tidak sempat melaporkan diri, cukup kopiahnya dilemparkan masuk ke dalam pekarangan rumah Kepala Adat. Jika si pria sudah melakukan demikian maka keluarga si gadis tidak boleh lagi 
mengganggu si pria tersebut karena persoalannya telah berada di tangan Kepala Adat.

Nilai filosofis atau philosophia merupakan gabungan dari kata philos (cinta) atau philia (persahabatan, tertarik kepada) dan sophos (kebijaksanaan, pengetahuan, keterampilan, pengalaman praktis, intelegensi). Kaitan dengan karya sastra bahwa karya sastra berisikan dengan perenungan dan pemikiran yang mendalam tentang Tuhan, kehidupan manusia, dan berbagai ajaran, maka konsep nilai filosofis harus dianggap sebagai sesuatu yang signifikan untuk dibicarakan dalam karya sastra. Perenungan dan pemikiran pun membutuhkan kemampuan akal. Gie (1987: 80) akal sebagai sumber daya mampu memperoleh nilai kebenaran, rasa sebagai sumber daya mampu memperoleh nilai keindahan, dan kehendak sebagai sumber daya mampu memperoleh nilai kebaikan atau kemuliaan.

Nilai filosofis dalam karya sastra tertentu mungkin berbeda dengan yang terdapat dalam karya sastra yang lain. Begitu juga terdapat perbedaan antara karya sastra dengan latar belakang budaya yang berbeda. Misalnya, secara filosofis, menepuk bahu seseorang bagi orang Jawa adalah penghinaan dan mengandung unsur kekurangajaran si pelaku, sedangkan bagi orang Bugis atau orang Sulawesi Selatan, perbuatan itu adalah hal yang biasa dan bahkan dianggap sebagai salah satu simbol keakraban. Contoh lain, orang Arab mengusap jenggot lawan bicara adalah sesuatu yang sopan dan menjadi tanda persahabatan, tetapi bagi orang Indonesia hal itu dianggap sebagai sesuatu yang kurang ajar (Mulyana, 2004). Dengan demikian, cara pandang atau kebijaksanaan hidup dan nilai filosofis dalam sebuah budaya terkadang sangat berbeda dengan budaya lain. Oleh karena itu, analisis terhadap nilai filosofis sebuah karya sastra harus memperhatikan prinsip makro dan mikro, prinsip universal dan lokal.

Untuk mengungkap nilai filosofis yang terdapat dalam puisi Aspar Paturusi, maka digunakan pendekatan hermeneutika Ricoeur. Model kerja hermeneutika Ricoeur dimulai dari pemahaman: (1) langkah simbolik atau pemahaman dari simbol ke simbol, (2) langkah pemberian makna oleh simbol serta penggalian yang cermat atas makna, dan (3) langkah yang benar-benar 
filosofis, yaitu berpikir dengan menggunakan simbol sebagai titik tolaknya. Agar ketiga langkah tersebut dapat dijalankan dengan baik, Ricoeur menyarankan tiga level pemahaman yang dikerjakan secara berurutan. Tiga level yang dimaksud, yakni (1) pemahaman semantik, (2) pemahaman reflektif, dan (3) pemahaman eksistensial. Tiga level pemahaman tersebut dijelaskan berikut ini.

Pemahaman pada level semantik diperoleh setelah melacak kata, baris, dan bait puisi yang dimaksud dalam kategori semantik denotatif dan atau konotatif. Pemahaman dalam kategori semantik denotatif dan konotatif diperoleh sesuai dengan data yang tersurat dan tersorot. Pemahaman pada level refleksif berada pada jenjang lebih tinggi, yakni pada level filosofis. Maksudnya, konstruk pemahaman pada level filosofis didadasarkan pada temuan maksud pada level semantik, yakni konstruk kebenaran yang dirujukkan pada fakta yang ditemukan pada kata, baik yang berciri denotatif dan atau konotatif. Dengan cara demikian didapatkan pemahaman filosofis melalui proses ulang balik antara pemahaman teks dengan pemahaman diri. Pemahaman diri dapat dilakukan melalui pemahaman orang lain, yakni kata, baris, dan bait yang telah terepresntasikan sebagai berbentuk dan terstruktur puisi. Pemahaman pada level eksistensial merupakan pemahaman yang paling kompleks karena penafsir dituntut mampu menampilkan dukungan atas kebenaran pemahaman yang ditemukan pada level refleksif. Dukungan yang dimaksud, yakni menampilkan motif-motif atau dorongan yang menjadi stimulus terepresentasikannya ide dalam penanda virtual puisi. Karena itu, pada tahap ini penafsir dituntut mampu mengungkap motif atau ide di balik representasi penanda virtual puisi terkait dengan pemahaman pada level reflektif (Ricoeur, 2003:32).

\section{PEMBAHASAN}

Pada bagian ini dibahas nilai filosofis yang bernuansa: kesadaran diri, keberanian, dan harga diri.

\section{Kesadaran Diri}

Puisi yang bernuansa tentang kesadaran diri terdapat pada puisi yang berjudul "Gunung dan Laut" sebagai berikut: 


\title{
Gunung dan Laut
}

\author{
gunung yang puncak \\ gunung yang kukuh \\ gunung yang diam \\ jadikanlah aku murid \\ agar aku paham \\ kearifan diam \\ kekekaran teguh \\ kebijakan nurani \\ laut yang luas \\ laut yang dalam \\ laut yang gelisah \\ jadikanlah aku murid \\ agar aku tahu \\ kedalaman ilmu \\ keluasan cakrawala
}

(Paturusi, 2015:46)

Pada puisi yang berjudul "Gunung dan Laut" tersebut ditemukan kata [jadikanlah aku murid]. Kata [jadikanlah aku murid] dapat dimaknai, yakni adanya pembimbing dan yang dibimbing, ada yang mengajar dan diajar, guru dan murid/siswa. Hal ini tentu mengindikasikan kesadaran diri bagi si murid atau yang diajar bahwa dirinya itu memiliki keterbatasan pemahaman. Pemaknaan ini akan semakin jelas ketika kata dan atau kelompok kata pada puisi tersebut diposisikan sebagai subjek dan predikat, seperti pemosisian berikut ini. Yang tergolong sebagai subjek, yaitu: gunung yang puncak, yang kukuh, dan yang diam, sedangkan predikatnya, yaitu: jadikanlah aku murid agar aku paham kearifan diam, kekekaran teguh, dan kebijakan nurani.

Kata gunung merupakan kata kunci pada posisi subjek. Secara denotasi, kata gunung dapat diartikan sebagai puncak yang menjulang tinggi, yang kukuh, dan yang diam, sedangkan secara konotasi kata gunung dapat diartikan sebagai keberuntungan, kemegahan, kelebihan dalam bentuk fisik maupun nonfisik. Sementara, kata murid sebagai kata kunci pada posisi predikat memilki makna, yakni kekurangan, kelemahan, sehingga perlu diisi. Kata gunung dan murid dari 
pemahaman semantik tersebut dapat ditarik binernya menjadi yang kuat dan yang lemah, yang kelebihan dan yang kekurangan, dan yang mengajar dan yang diajar.

Dari pemahaman semantik itu, maka dapat diketahui refleksifnya bahwa sesuatu yang dikatakan kuat manakala ada yang lemah, sesuatu yang dikatakan berlebih manakala yang ada kekurangan, seseorang yang dikatakan mengajar (guru) manakala ada yang diajar (murid). Guru adalah manusia yang dianggap berilmu sehingga ia perlu membagi ilmunya kepada yang kurang berilmu, yakni kepada murid. Hubungan keduanya merupakan hubungan yang bersifat mutualisme. Artinya, hubungan tersebut saling menguntungkan di antara kedua belah pihak. Guru tidak dikatakan sebagai guru manakala ilmunya tidak diajarkan kepada orang lain (kepada muridnya) dan sebaliknya murid tidak dikatakan sebagai murid apabila tidak mempunyai guru.

Pada gunung ataupun laut, keduanya mengandung potensi kekayaan yang luar biasa banyaknya untuk kepentingan manusia dan sekaligus menjadi bahan pelajaran ataupun renungan bagi orang yang sadar tentang ciptaan Allah, seperti dalam (An Nahl, 16:15) "Dan Dia menancapkan gunung-gunung di bumi supaya bumi itu tidak goncang bersama kamu, (dan Dia menciptakan) sungai-sungai dan jalan-jalan agar kamu mendapat petunjuk."

Secara eksistensial kata gunung dalam kajian ini diibaratkan sebagai guru bagi si aku murid sehingga si aku murid ingin berguru kepadanya tentang kearifan diam, kekekaran teguh, dan kebijakan nurani. Keberadaan gunung di muka bumi ini memberikan manfaat yang luar biasa banyak terhadap semua mahluk yang ada dipermukaan bumi, khususnya kepada mahluk manusia, seperti tambang emas, minyak, nikel, dan sebagainya. Di samping itu, gunung yang menancapkan pasakpasaknya ke dalam perut bumi menjadi penyeimbang bumi agar bumi tidak mengalami kemiringan, seperti yang termaktub dalam al-Quran, "Bukankah Kami telah menjadikan bumi itu sebagai hamparan, dan gunung-gunung sebagai pasak? (An Naba', 78: 6-7).

Dari uraian semantik, refleksif, dan eksistensial di atas, maka dipahami bahwa kesadaran diri merupakan motivasi untuk berinteraksi dengan pihak lain dalam meraih kemajuan hidup. Widiasusanto menyatakan bahwa kesadaran diri 
merupakan proses mengenali motivasi, pilihan, dan kepribadian kita lalu menyadari pengaruh faktor-faktor tersebut atas penilaian, keputusan dan interaksi kita dengan orang lain. (http://kumpulanmakalah widiasusanto. blogspot. co.id/2015/04/makalah-tentang-kesadaran.html) diakses, 7 Maret 2017.

\section{Keberanian}

Puisi yang bernuansa tentang keberanian terdapat pada puisi yang berjudul "Perahu" sebagai berikut:

\section{Perahu}

sebuah perahu dengan layar sobek bergerak melawan angin dan ombak adakah cemas mengguncangkan sang awak tapak tangannya kokoh pada kemudi

tangan boleh luka layar boleh sobek dan angin yang pernah hilang di utara kini menderu dari timur

angin menghalau arah angin memainkan nasib para awak adakah jiwa yang telah menyelami laut dalam adakah kulit yang telah berbau lumut karang menyerahkan nasib pada ombak dan angin

(Paturusi, 2015:60)

Puisi yang berjudul "Perahu" ditemukan kata atau kelompok kata yang merujuk pada makna keberanian (sikap pemberani). Kata atau kelompok yang dimaksud tersebut adalah layar sobek, melawan angin dan ombak, Kata atau kelompok kata layar sobek, melawan angin dan ombak dimaknai sebagai pemberani karena hanya orang pemberanilah (yang memiliki sikap keberanian) yang mau mamakai layar sobek dan atau melawan angin dan ombak. Pemahaman ini mengenai keberanian semakin jelas ketika kata atau kelompak kata pada puisi tersebut diposisikan dalam posisi subjek dan predikat. Kata atau kelompok kata yang tergolong subjek adalah sebuah perahu, sedangkan predikatnya adalah dengan layar sobek, bergerak melawan angin dan ombak, mengguncangkan sang awak, tapak tangannya kukuh pada kemudi. 
Secara semantik kata perahu dapat dimaknai sebagai alat transportasi untuk menangkap ikan bagi para nelayan, alat transportasi untuk mengangkut barang antara pulau, alat transportasi untuk orang dari satu pulau ke pulau lainnnya. Perahu bagi orang Bugis-Makassar merupakan alat transportasi yang amat dekat dalam kehidupannya, terutama mereka yang berdiam di sekitar pantai. Layar sobek berarti tirai atu kain yang tidak utuh, terdapat lubang-lubang sehingga tidak memberi hasil yang maksimal untuk dipakai berlayar; bergerak melawan angin dan ombak berarti bergerak menghadapi tantangan walaupun merasa cemas; tapak tangannya kukuh pada kemudi berarti kuat terpancang pada tempatnya atau tidak mudah roboh.

Secara refleksif kata perahu dapat dimaknai sebagai simbol masyarakat yang berdiam di sekitar pantai atau sungai, tetapi yang lebih dominan arahnya ke pantai atau laut daripada ke arah sungai karena dalam realitasnya bahwa banyak orang yang tinggal d sekitar bantaran sungai, tetapi mereka tidak memiliki perahu. Sebaliknya, orang yang berumah di sekitar pantai selalu berusaha untuk memiliki perahu karena perahu dianggap sebagia bagian dari kehidupan mereka. Perahu bagi masyarakat Bugis-Makassar dan khususnya asal tanah kelahiran penulis puisi (Aspar Paturusi), yaitu Tanah Beru tidak bisa dipisahkan karena Tanah Beru merupakan tempat pembuatan perahu Pinisi, yang tersohor di Nusantara ini dan bahkan terkenal sampai ke mancanegara.

Dalam epos I Lagaligo, perahu Pinisi dipakai oleh Sawerigading untuk menjemput calon istrinya, yang bernama We Cudai di negeri Cina (Tiongkok) sekitar akhir Abad ke-15. Hal ini berarti bahwa perahu Pinisi tidak hanya digunakan untuk transportasi antarpulau, tetapi juga antara bangsa. Bahkan, tujuh buah layar yang berkibar pada perahu Pinisi disimbolkan sebagai kemampuan untuk melayari tujuh Samudra besar di dunia. Perahu Pinisi di era canggih ini dijadikan sebagai perahu Wisata atau kapal Pesiar. http://indonesiaexplorer.net/pinisi-kapal-tangguh-nusantara-dari-bulukumba.html. Diakses 15-4-2017

Kata atau kelompok kata dengan layar sobek, bergerak melawan angin dan ombak, mengguncan sang awak, tapak tangannya kukuh pada kemudi, secara 
umum merujuk ke makna keberanian. Orang yang berani atau yang bernyali saja dapat memakai layar yang sobek, menantang angin dan ombak, mengguncang sang awak, tetapi tangannya kukuh pada kemudi. Orang penakut akan menggulung layarnya yang sobek, memarkir perahunya di tepi pantai ketika angin dan ombak besar datang menderu-deru atau saling berkejaran, seperti perlombaan pada pacuan kuda. Namun, bagi pelaut Bugis-Makassar, angin dan ombak dapat menjadi sahabat dalam berlayar sehingga mereka tidak merasa cemas ketika angin dan ombak datang menderu-deru.

Berdasarkan pemahaman semantik dan refleksif tersebut, maka dapat ditarik pemahaman eksistensial bahwa salah satu sifat yang dimiliki orang BugisMakassar adalah keberaniannya dalam berlayar. Mereka memiliki prinsip bahwa ketika layar telah dikembangkan maka pantang perahu surut kembali ke pantai walaupun menghadapi resiko yang berat, termasuk nyawa sekalipun sebagai taruhannya (dalam bahasa Makassar: Kuaaleanna tallanga na toaliya). Prinsip mereka bukan tanpa didasarkan pada pertimbangan yang matang, melainkan penuh dengan pertimbangan yang matang, seperti persiapan fisik anak buah kapal (perahu) dan fisik perahu serta pengetahuan mereka mengenai ilmu perbintangan yang matang dan yang terakhir adalah ke pasrahan mereka kepada PattotoE, Dewata Seuwa (Bugis), Tau ri A'rana (Makassar), yang berarti Tuhan Yang Mahakuasa. Selain itu, laut bagi orang Bugis-Makassar merupakan sumber penghidupan mereka dan ini sejalan pula dengan QS. An-Nahl 16 : 14, yang artinya: “

Dan Dia-lah, Allah yang menundukkan lautan (untukmu) agar kamu dapat memakan daripadanya daging yang segar (ikan), dan kamu mengeluarkan dari lautan itu perhiasan yang kamu pakai; dan kamu melihat bahtera berlayar padanya, dan supaya kamu mencari (keuntungan) dari karunia-Nya, dan supaya kamu bersyukur."

Dengan demikian, kata berani bagi orang Bugis-Makassar merupakan tindakan yang penuh pertimbangan dalam berbagai aspek demi kemaslahatan dan bukan dengan tindakan emosional, yang penuh dengan rasa amarah. Oleh karena itu, berani dianggap sebagai sikap yang terpuji dan perlu dilestarikan, seperti 
Sultan Hasanuddin, beliau dengan keberaniannya melawan tentara penjajah (Belanda) sampai titik darah penghabisan. Hal tersebut berbeda dengan kata nekat. Nekat adalah sikap yang didasari oleh nafsu amarah sehingga tidak lagi mau mendengar nasihat atau petuah dari orang-orang yang dituakan dan atau dari pemerintah.

\title{
Harga Diri
}

Puisi yang bernuansa tentang harga diri terdapat pada puisi yang berjudul "Surat Kakek" sebagai berikut:

\author{
Surat Kakek \\ disegani seluruh bangsa \\ tujuh kali juara piala dunia \\ piut, ini impian generasi kakek \\ hidup yang terhormat \\ 'sipakatau sipakalebbi' \\ pesan leluhur orang bugis, nak \\ saling menghormati antara sesama \\ saling memanusiakan sebagai manusia
}

(Paturusi, 2015:94)

Puisi yang berjudul "Surat Kakek" ditemukan kata atau kelompok kata yang merujuk pada makna harga diri (teladan). Kata atau kelompok kata yang dimaksud tersebut adalah disegani seluruh bangsa, tujuh kali juara piala dunia, hidup yang terhormat, sipakatau sipakalebbi, saling menghormati antara sesama, dan saling memanusiakan sebagai manusia dimaknai sebagai harga diri. Pemahaman mengenai harga diri semakin jelas ketika kata atau kelompak kata pada puisi tersebut diposisikan dalam posisi subjek dan predikat. Kata atau kelompok kata yang tergolong subjek adalah Piut, sedangkan kata atau kelompok kata yang tergolong predikat adalah disegani seluruh bangsa, tujuh kali juara piala dunia, hidup yang terhormat, sipakatau sipakalebbi, saling menghormati antara sesama, dan saling memanusiakan sebagai manusia.

Secara semantik kata piut dapat dimaknai sebagai cucu (regenerasi) kelima atau cucu yang sudah dianggap jauh bagi orang Bugis-Makassar. Cucu 
(generasi) yang memiliki harga diri adalah generasi yang memilki prestasi yang membanggakan sehingga orang (generasi) lain menyeganinya, seperti yang tampak pada predikat tujuh kali juara piala dunia. Hal lain yang dapat membangkitkan harga diri (self esteem) adalah sipakatau sipakalebbi (saling menghormati antara sesama manusia atau saling memanusiakan sebagai manusia). Dalam kearifan lokal Bugis-Makassar sipakatau sipakalebbi dapat diimplementasikan dengan berbagai cara, yaitu a) bekerja keras, b) pantang meminta, dan c) menjaga amanah.

Dari pemahaman semantik di atas, maka secara refleksif diketahui bahwa harga diri adalah bekerja keras. Bekerja keras merupakan salah satu fondasi untuk mengangkat harga diri (bangsa) karena hanya orang (bangsa) yang memiliki semangat bekerja keras dapat menghasilkan prestasi yang membanggakan, seperti petuah nenek moyang kami "Resopa temmangingi malomo naletei Pammase Dewata" (Usaha yang sungguh-sungguh tanpa mengenal lelah mendapat rida dari Tuhan yang Mahakuasa). Orang yang memiliki harga diri mempunyai sikap pantang meminta kepada orang lain karena meminta kepada orang lain akan merendahkan harga diri. Orang yang meminta berarti tangannya di bawah, sedangkan orang yang memberi bearti tangannya di atas. Itulah sebabnya dikatakan bahwa orang yang memberi lebih mulia daripada orang yang menerima. Dengan demikain, harga diri individu (bangsa) tidak dapat terbangun jika tidak berpantangan dengan perilaku meminta-minta.

Salah satu ciri bagi orang yang memiliki harga diri adalah menjaga amanah. Bila diberi amanah, maka amanah itu dijaganya dengan baik dan bahkan dia siap mempertaruhkan nyawanya demi mempertahankan amanah (kepercayaan) yang dititipkan kepadanya. Orang yang seperti ini dalam suku Bugis-Makassar disebut tau memeng tau atau tau tojeng taua. Wahid (2010:54-55) menyatakan bahwa kata tau tojeng taua (benar-benar manusia) berarti manusia yang bertanggung jawab, dapat diajak bekerjasama, dapat menghargai orang lain, dan memilki sifat sopan santun dalam pergaulan, sedangkan poro tau (sekedar manusia) adalah manusia yang tidak bertanggung jawab, tidak dapat diajak 
bekerjasama karena kata-katanya tidak dapat dipercayai, dan tidak memilki adat sopan santun dalam pergaulan.

Dari pemahaman semantik dan reflesif tersebut, maka pemahaman secara eksistensial diketahui bahwa harga diri dibangun dari usaha yang sungguhsungguh tanpa mengenal lelah dan apalagi putus asa. Di samping itu, harga diri juga terbangun dengan adanya perilaku yang sopan santun dalam pergaulan sehari-hari, saling menghormati antara sesama manusia (sipakatau sipakalebbi). Konsep sipakatau sipakalebbi dari warisan moyang kami ternyata memiliki makna yang substansial dalam kehidupan bermsyarakat, baik pada era dahulu maupun pada era kekinian karena konsep ini sangat mempedulikan nilai-nilai kemanusian. Nilai-nilai kemanusiaan dijunjung tinggi oleh setiap bangsa di dunia, dalam keadaan apapun, termasuk dalam perang. Dalam perang, lawan yang sudah kalah harus tetap diperlakukan secara manusiawi, seperti dalam Quran, Surat AlInsan, ayat 8 yang artinya: "Dan mereka memberikan makanan yang disukainya kepada orang miskin, anak yatim, dan orang yang ditawan.“ Hal ini menunjukkan betapa pentingnya saling memanusiakan dalam pergaulan kehidupan sehari-hari. Mc Dougall (1926) menyatakan bahwa harga diri adalah pengatur utama perilaku individu atau merupakan pemimpin bagi semua dorongan. Kepadanya bergantung kekuatan pribadi, tindakan, dan integritas diri.

\section{SIMPULAN}

Kesadaran diri merupakan bentuk pemahaman diri bahwa apapun predikat yang disandang tidak pernah terlepas dari predikat lain yang disandang orang lain. Ketika ada yang dikatakan kuat, maka ada pula yang dikatakan lemah; ketika ada yang dikatakan kaya, maka ada pula yang dikatakan miskin; ketika ada yang dikatakan cantik, maka ada pula yang dikatakan jelek; jika ada yang dikatakan pelajar, maka ada pula yang dikatakan pengajar. Dengan adanya kesadaran diri seperti itu, maka tidak sepantasnya rasa kesombangan terpelihara dalam diri setiap individu.

Keberanian merupakan bentuk sikap yang tegas terhadap suatu putusan. Bentuk sikap yang tegas tersebut didasarkan pada pertimbangan yang matang 
dalam berbagai aspek agar dapat memberikan manfaat dalam hidup dan kehidupan. Dengan demikian, keberanian tidak berlandaskan pada rasa egois, emosional, dan irrasional karena hal ini hanya memberi dampak negatif dalam hidup dan kehidupan.

Harga diri rupanya tidak tercipta dengan sendirinya, melainkan ia tercipta dengan kerja keras atau secara sungguh-sungguh sehingga dapat membuahkan hasil yang diharapkan. Oleh karena itu, hanya orang yang bekerja keras pantas mendapatkan harga diri dan bukan orang pemalas.

\section{DAFTAR PUSTAKA}

Abrams, M.H. (1981). A Glossary of Literary Terms. Cet.IV. New York: Holt, Rinehart and Winston.

Al-Jazairi, A.B.J. (2003). Ensiklopedia Muslim (Minhajul Muslim). Diterjemahkan Fadhli Bahri. Jakarta: Darul Falah.

Al-Qarni, A. (2008). La Tahzan (Jangan Bersedih). Terjemahan Samson Rahman. Jakarta: Qisthi Press.

Amaluddin. (2009). Bentuk, Fungsi, Nilai, dan Strategi Pemertahanan Tradisi Lisan Nyanyian Rakyat Bugis. Disertasi tidak diterbitkan. Malang: PPs UM Malang.

Amir, H. (1990). Pendidikan Sastra Lanjut. Malang: IKIP Malang.

Gabriel, R.H. (1991). Nilai-nilai Amerika: Kelestarian dan Perubahan. Terj. Paul Surono Hargosewoyo dan Suntingan Alex H. Rambadeta. Yogyakarta: Gajah Mada University Press.

Gazalba, S. (1998). Sistematika Filsafat III. Jakarta: Bulan Bintang.

Gie, T. L. (1987). Garis Besar Filsafat. Yogyakarta: Penerbit Karya.

Iskandar, T. (1998). Kamus Dewan. Kuala Lumpur: Dewan Bahasa dan Pustaka.

Jassin, H.B. (1977). Tifa Penyair dan Daerahnya. Jakarta: Gunung Agung.

Moeing, A. (1988). Menggali Nilai-Nilai Budaya Bugis-Makassar dalam Sirin'na Pesse. Makassar: Mapress.

Muliadi. (2014). Nilai Multikultural Teks Puisi Husni Djamaluddin dalam Kajian Hermeneutika. Disertasi tidak diterbitkan. Malang: PPs UM Malang.

Mulyana. R. (2004). Mengartikulasikan Pendidikan Nilai. Bandung: Alfabet. 
Mustafa, M.Y., Wanua T. \& Anwar N. (Editor). (2003). Siri' dan Pesse': Harga Diri Orang Bugis, Makassar, Mandar, dan Toraja. Makassar: Pustaka Refleksi.

Paturusi. A. (2015). Perahu Badik: Membaca Laut (Reading the Sea). Jakarta: Kosa Kata Kita.

Pradopo, R.D. (2005). Pengkajiam Puisi. Yogyakarta: Gadjah Mada University Press.

Puteh, O. (1996). Cerpen-Cerpen Keris Mas: Satu Tinjauan dari Sisi Nilai Nasionalisme. Dalam Siti Aisyah Murad (Ed), Konsep Nilai dalam Kesusastraan Melayu (hlm. 25-36). Kuala Lumpur: Dewan Bahasa dan Pustaka.

Ratna, N.K. (2004). Teori, Metode, dan Teknik Penelitian Sastra. Yogyakarta: Pustaka Pelajar.

Ricouer, P. (2003). Filsafat Wacana. Terjemahan Masnur Hery. Yogyakarta: IRCiSod.

Saryono, D. (2009). Dasar Apresiasi Sastra. Yogyakarta: Elmatera Publishing.

Teeuw. (1984). Sastra dan Ilmu Sastra. Jakarta: Pustaka Jaya.

Wahid, S. (2010). Manusia Makassar. Makassar: Refleksi. 